\title{
Penetration tests on the DS-2 Mars microprobes: penetration depth and impact accelerometry
}

\author{
Ralph D. Lorenz ${ }^{\mathrm{a}, *}$, Jeffrey E. Moersch ${ }^{\mathrm{b}}$, J. Andy Stone ${ }^{\mathrm{c}}$, A. Ron Morgan Jr ${ }^{\mathrm{c}}$, Suzanne \\ E. Smrekar ${ }^{\mathrm{c}}$ \\ ${ }^{\mathrm{a}}$ Lunar and Planetary Lab, University of Arizona, 1629 E. University Blvd, Tucson, AZ 85721-0092, USA \\ ${ }^{\mathrm{b}}$ NASA Ames Research Center, National Research Council, MS 239-4, Moffett Field, CA 94043, USA \\ ${ }^{c}$ Jet Propulsion Lab, California Institute of Technology, 4800 Oak Grove Drive, Pasadena, CA 91109, USA
}

Received 5 July 1999; accepted 16 August 1999

\begin{abstract}
We describe the results of three separate sets of impact tests conducted during the development of the DS-2 Mars Microprobe mission. As well as indicating the promise of penetration to $\sim 0.5 \mathrm{~m}$ depth on Mars, these tests show the utility of accelerometer data in determining the penetration depth, the hardness of the surface material and the existence of layers, and the presence of coarse-grained material. Various lessons learned in instrumentation and operation, airgun testing and target characterization, and penetrator design for reliable separation, are discussed. (C) 2000 Elsevier Science Ltd. All rights reserved.
\end{abstract}

\section{Introduction}

Penetrators are a relatively untried vehicle type for planetary exploration, although concepts for such vehicles are well over 20 years old (Simmons, 1977). The Comet Rendezvous/Asteroid Flyby (CRAF) mission featured a comet penetrator, but the mission was cancelled in 1992, although see Boynton and Reinert (1995). The Mars-96 mission included two large penetrators (Surkov and Kremnev, 1998) but was lost in a launch failure. The Japanese Lunar-A project will send two penetrators to the Moon (Mizutani, 1995) to arrive in the next decade.

The first planetary penetrator mission to explore the surface of another world, the subject of the present paper, will be the NASA New Millennium Program's DS-2 Mars Microprobe mission, with arrival of two small penetrators anticipated on 3 December 1999 (Smrekar et al., 1999).

\footnotetext{
* Corresponding author. Tel.: + 1-520-621-5585; fax: + 1-520-6214933.

E-mail address: rlorenz@lpl.arizona.edu (R.D. Lorenz).
}

The deceleration history of a projectile may be used to infer the strength and homogeneity of the target material. This method was proposed for early lunar missions (e.g. Beswick, 1964; McCarty et al., 1964). Impact accelerometry will be performed on the anchor harpoons of the Rosetta lander (Kömle et al., 1997) to deduce cometary subsurface structure, and on the Huygens probe (Lorenz et al., 1994) to determine the hardness of Titan's unknown surface.

Although terminal ballistics of projectiles has been a subject of investigation for centuries and some crude estimation of likely penetration depths for given impact conditions can be made, the penetration process for different projectile shapes and targets is not sufficiently well-understood that correct interpretation of impact accelerometer data can be performed without some empirical investigation. In this paper we describe three sets of impact test and their results regarding impact accelerometer data and penetration mechanics. The aim of this paper is not to explore theoretical models of penetration, but rather to present the experience gained in these tests.

The first series of tests were development tests undergone to validate the DS-2 design, to ensure cor- 
rect deployment of the vehicle and to demonstrate the survival of its various components. These tests were conducted over a period of approximately 2 years starting in April 1996 at the Energetic Materials Research and Test Center (EMRTC) operated by New Mexico Tech in Socorro, New Mexico. The evolution of the penetrator design in the light of these tests is discussed by Stone and Rivellini (1998). A preliminary investigation of the penetration distance data from these tests was presented in Lorenz et al. (1999).

A second series of tests has been underway since November 1998 using an airgun at the Lunar and Planetary Laboratory; although these tests are limited to impact speeds of around $50 \mathrm{~m} / \mathrm{s}$ (compared with the expected $200 \mathrm{~m} / \mathrm{s}$ impact of DS-2 on Mars) they can be performed with instrumented projectiles and more closely-controlled target stratigraphy. The tests have demonstrated the ability of an accelerometer mounted in a DS-2 type forebody to resolve layering in the target.

A third, short series of tests was conducted in April 1999 with the intent of recording impact accelerometer data under more-or-less flightlike conditions, using instrumentation equivalent to that on the probes presently on their way to Mars.

Before discussing these three series of tests and their results, we first introduce the DS-2 mission and its flight instrumentation which provide the motivation for these tests.

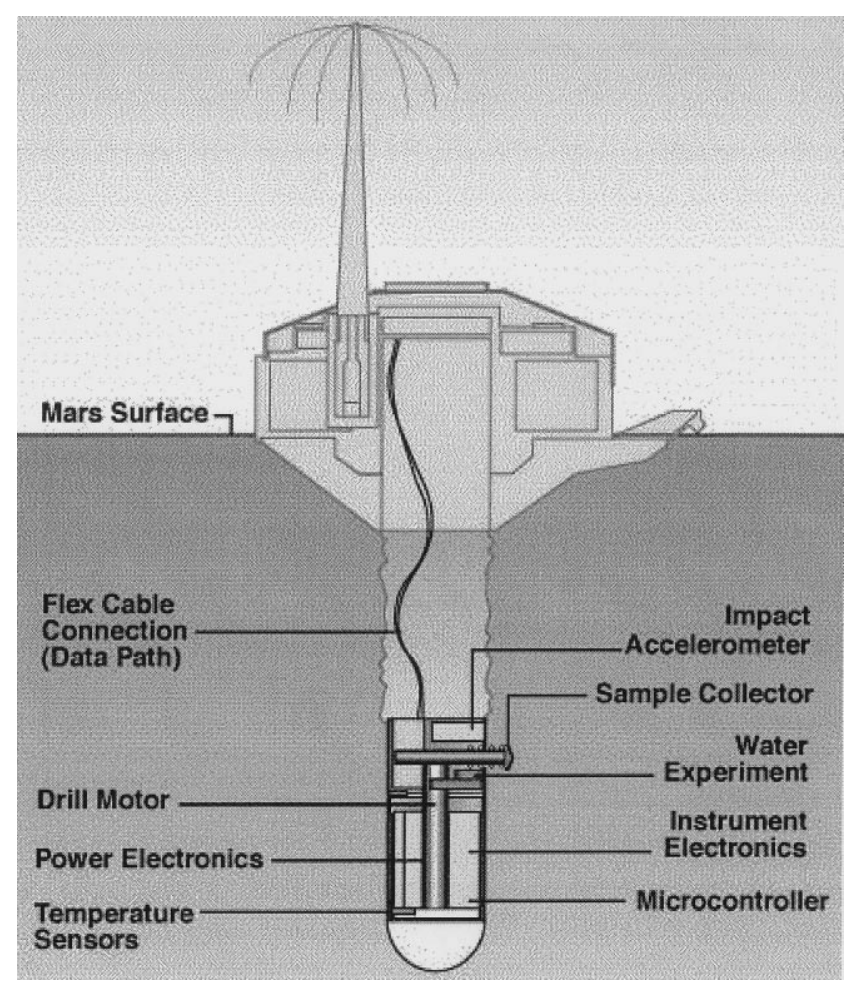

Fig. 1. Schematic of deployed DS-2 Penetrator.

\section{DS-2 Mission and impact accelerometer investigation}

The Deep Space 2 ('DS-2') Mars Microprobe mission is the second flight mission in NASAs New Millenium program which aims to validate new technologies for future space missions. It features two miniaturized probes, each consisting of a penetrating forebody and an aftbody which will remain on the surface (Fig. 1). Each probe is encased in a frangible entry shell which shatters on impact with the Martian surface at approximately $200 \mathrm{~m} / \mathrm{s}$. The two microprobes were launched on 3 January 1999 towards Mars attached to the Mars Polar Lander, from which they will be released a few minutes before entering the Martian atmosphere.

The microprobes carry: a descent accelerometer to characterize the atmospheric structure during entry; an impact accelerometer to determine the depth of burial and to characterize the hardness of the surface and infer the presence of smallscale layers; a water detection experiment; and a soil thermal conductivity experiment. The DS-2 mission and its investigations are described in detail in Smrekar et al. (1999).

The deceleration history of a projectile may be used to infer the strength and homogeneity of the target material. Additionally, the deceleration history may be integrated to derive an estimate of the penetration depth of the projectile. Both of these aspects are of interest for DS-2 (Moersch and Lorenz, 1998), which will land around $75^{\circ} \mathrm{S}$ latitude on Mars, on the polar layered terrain (see, e.g. Thomas et al., 1992; Vasavada et al., 1999) which appear to be composed of layers of dust and ice-rich material.

First, the correct interpretation of the soil conductivity experiment and the water detection experiment rely on a reasonable estimate of the deployment depth of the forebody, since the depth at which water is or is not detected by the two DS-2 probes is significant for comparison with the related (but more sensitive) measurements to be made $50-60 \mathrm{~km}$ further south by the Mars Polar Lander.

Secondly, since layers have been detected as thin as imaging resolution has allowed (presently a few meters), it is possible that layering occurs on much smaller scales, and may be detectable as soft (dustrich) and hard (ice-rich) layers in the accelerometer signal. Small-scale layers will be investigated by the Mars Polar Lander, but the local stratigraphy may be somewhat different at the DS-2 sites.

\subsection{Flight hardware}

The aftbody is a complex shape (see Fig. 1) but roughly speaking is cylindrical or ellipsoidal, $\sim 14 \mathrm{~cm}$ in diameter and $12 \mathrm{~cm}$ deep.

The forebody is a cylinder with a hemispherical nose 
and is $10 \mathrm{~cm}$ long, $39 \mathrm{~mm}$ in diameter, made from a steel tube and its mass is $670 \mathrm{~g}$. The hemispherical nose cap, attached by a screw fitting, is made of tungsten, in order to bring the center of mass of the forebody-aftbody assembly as far forward as possible to ensure entry stability (Braun et al., 1997). Within the steel tube is a triangular prism made from three circuit boards carrying a microcontroller and instrument electronics and inside this prism is a motor used to drive the drill for the water detection experiment. At the top of the cylinder is an aluminum alloy block, containing the latter experiment, a cavity from which the umbilical cable to the aftbody deploys, and the impact accelerometer.

The impact accelerometer hardware in each of the two DS-2 microprobes consists of a uniaxial accelerometer aligned with the long $(z)$ axis of the probe, housed in the rear end of the forebody. The accelerometer is a ruggedized piezoresistive design (Endevco Model 7570A) with a measurable input range of $-10,000-30,000 \mathrm{~g}$ and a nominal (14 bit) precision of $10 \mathrm{~g}$. The accelerometer is polled by the probe's advanced microcontroller at a sampling rate of $25 \mathrm{kHz}$ in a circularly-addressed memory buffer, starting approximately $100 \mathrm{~s}$ before impact. The entire measurement chain is in the forebody, although the batteries are in the aftbody, as is the radio transmitter. Only the final $30 \mathrm{~ms}$ of accelerometer data, starting $6 \mathrm{~ms}$ before impact detection are stored for later transmission, but this should capture the entire impact event. Thus the total data return from each penetrator's accelerometer will be about $1.5 \mathrm{~kb}$.

\section{Development tests}

Extensive testing was required to refine the mechanical design and demonstrate a good probability of mission success. Specific goals of the test program are listed below.

- Demonstrate reliable emplacement. At these modest impact speeds, projectiles can skip or bounce, rather than penetrate, especially in soft targets and at high incidence or attack angles. These concerns led to shaping of the front of the aftbody with tines to reduce skip. These aspects are discussed at length in Stone and Rivellini (1998).

- Perform sample acquisition. Various strategies to obtain subsurface samples were attempted, including scraper hooks at the side of the forebody, a 'digestive tract' with a hole at the apex, and simple collection of soil at the back of the forebody. All of these strategies turned out to be unsuccessful, either by failing to reliably acquire a large enough sample, or by preferentially acquiring near-surface material. U1- timately, the technically more complex solution of using a sampling drill had to be employed.

- Test component survivability. Although empirical techniques in electronics packaging are known, the internal survivability of many components to shock loading is not well-known; this is particularly the case for novel items such as the tunable diode laser in the water detection experiment. Challenging items also included the batteries, the crystal oscillator for the radio system, and the sample drill motor and gearing.

These tests used a $15 \mathrm{~cm}$ diameter airgun (Fig. 2) built by the Sandia National Laboratory and operated by EMRTC. The microprobe is placed in a foam sabot (shaped to provide the desired angle of attack, 'AoA') inside the gun. The gun is pumped to high pressure until a burst disk fails and projects the microprobe towards the target. The sabot is made from pie-shaped segments; a concavity in the rear of the sabot causes the back pressure to force the segments apart, separating the sabot from the projectile before impact (Fig. 3). X-ray flash photography (Fig. 4) and streak cameras are used to verify the AoA and velocity. Breakwires were also used on some shots to verify velocity.

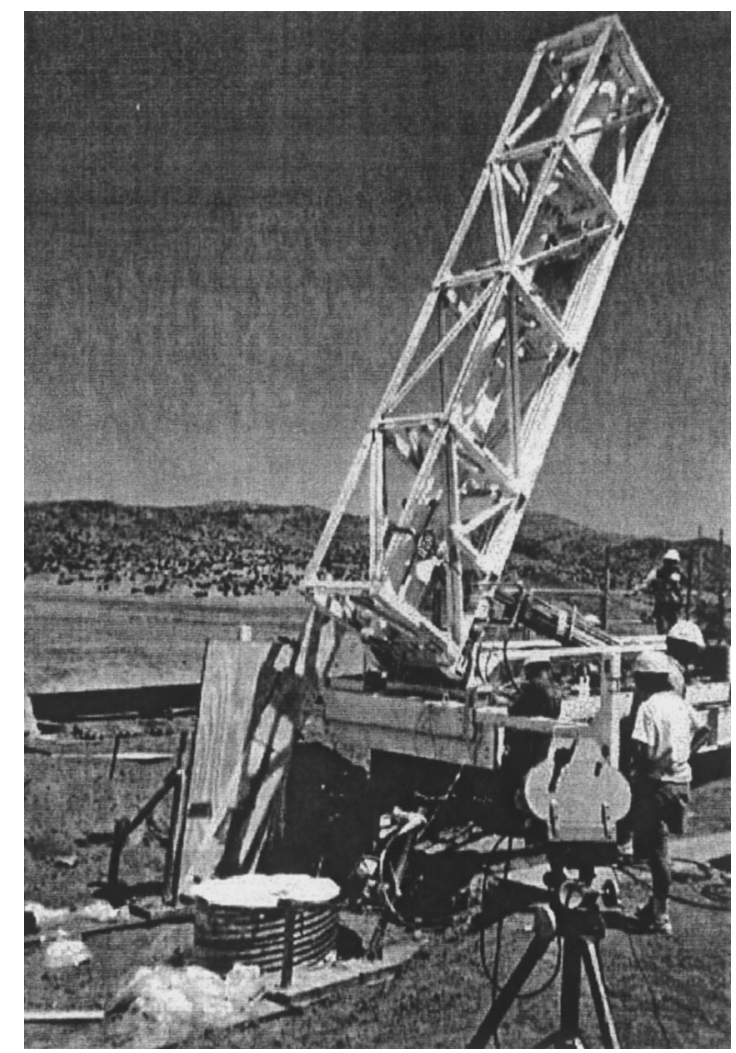

Fig. 2. Airgun at EMRTC. The gun itself is the white barrel in the center of the truss framework. The truck contains the valves and equipment: a separate compressor trailer provides the high-pressure air. 


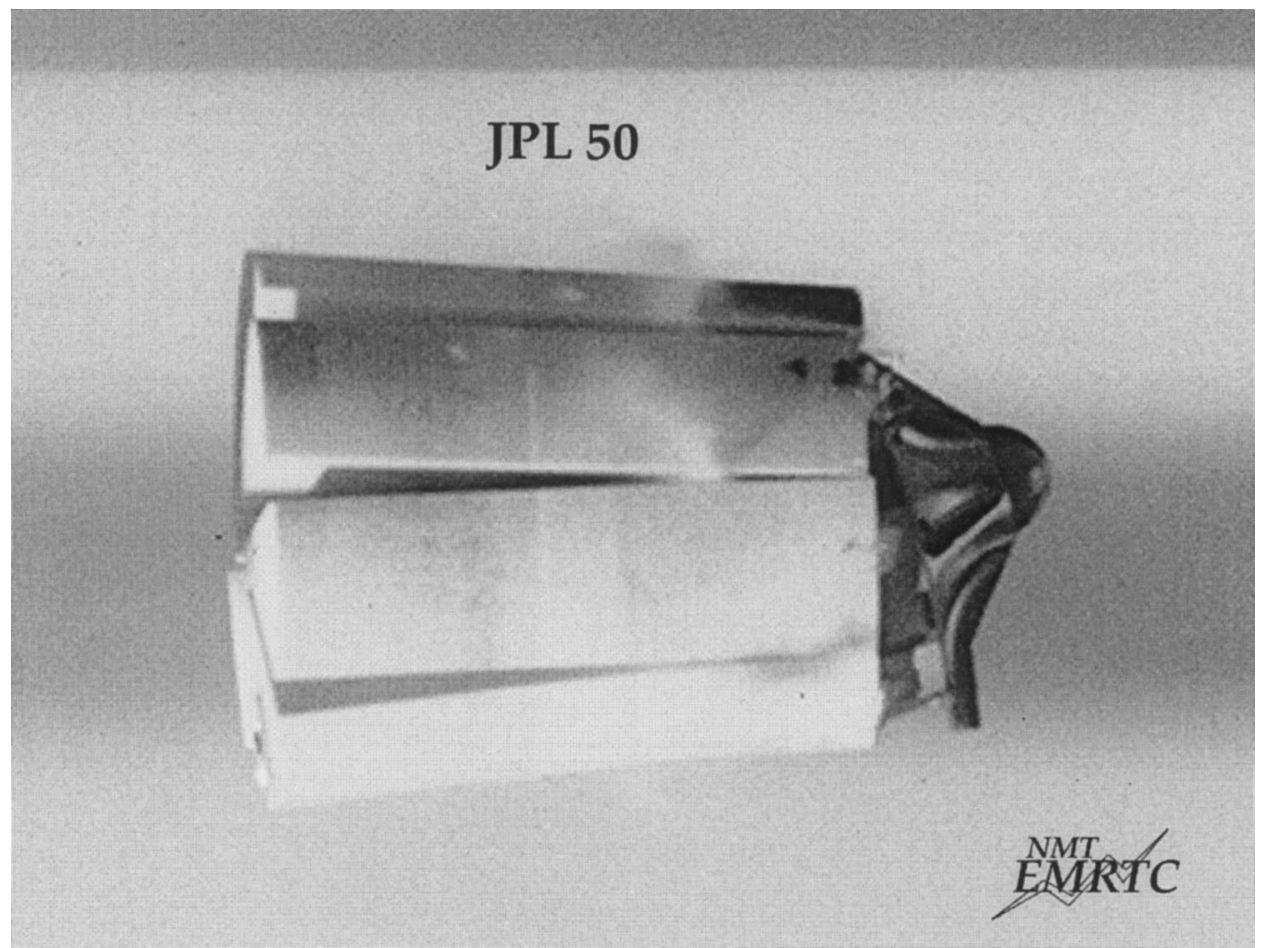

Fig. 3. High-Speed Streak Photograph, from slightly to the rear of the free-flying penetrator and sabot. The foam sabot segments are starting to peel away from the rear of the penetrator. The nose of the forebody can be seen projecting to the left of the photograph.

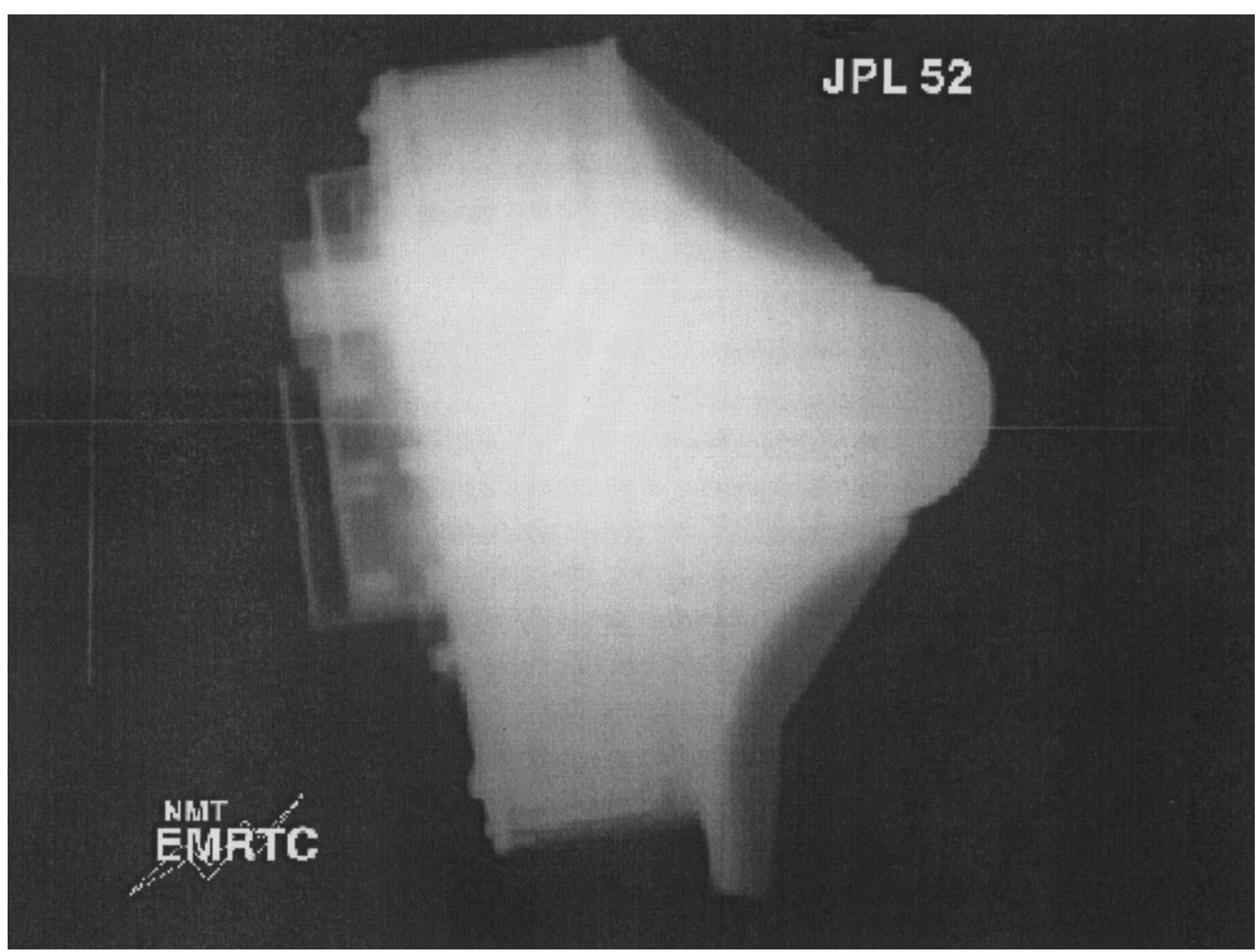

Fig. 4. X-ray photograph of a flight-like penetrator configuration. The strong shadow of the central body is apparent, as are the weak shadows of the tines on the front face of the aftbody and the components mounted on the back side. 
-

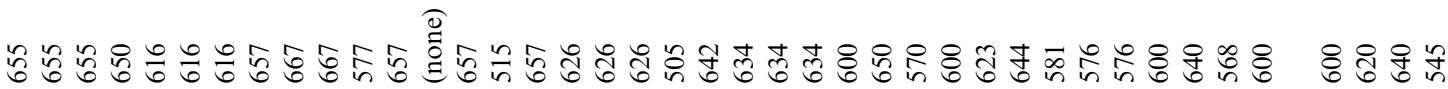

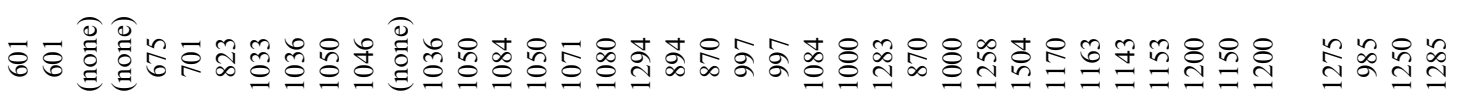
$\varangle$

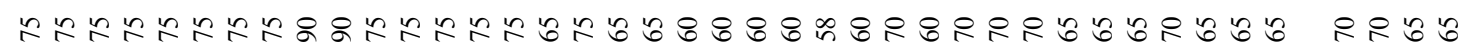

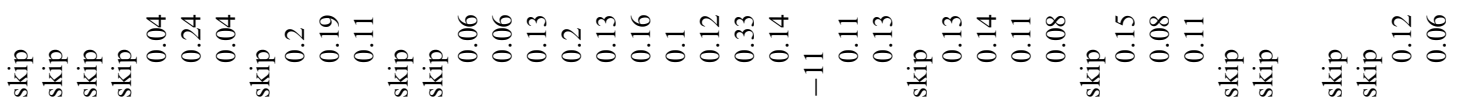

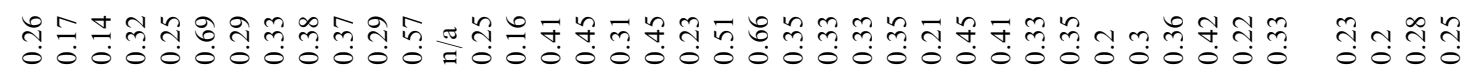

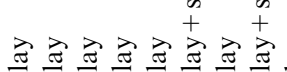

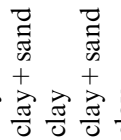

$\frac{5}{n}$ 


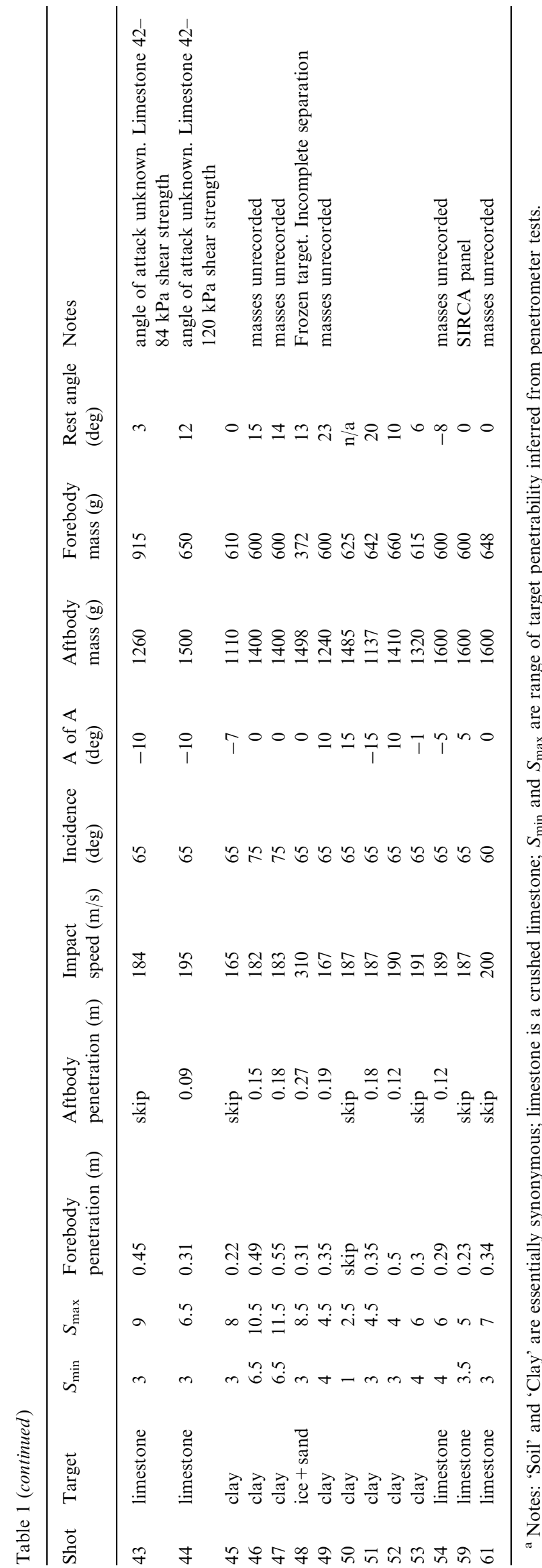

The projectile velocity is determined by several factors, principally the projectile mass and the pressure at which the burst disc fails. The velocity can be 'fine tuned' by placing the projectile at different positions along the barrel of the gun.

The target material is frequently New Mexico native clay, but can be other planetary analogs (sand, crushed limestone, etc.). Two tests were performed with frozen 'wet sand' targets, although the logistics and costs associated with freezing the target and keeping it chilled with liquid nitrogen in the desert were formidable, and ultimately prohibitive. One difficulty with forming soil/ ice targets is that homogeneity is nearly impossible to achieve - the mixture tends to freeze in a nonuniform manner, with ice concentrating at the bottom of the target.

The test conditions and results are summarized in Table 1.

\subsection{Impact accelerometry}

Attempts were made on several shots to obtain accelerometry data during the impact, not so much for scientific interpretation, as to document the actual deceleration pulse experienced by the components under test. Attempts to record accelerometer signals using trailing steel wires and a storage oscilloscope

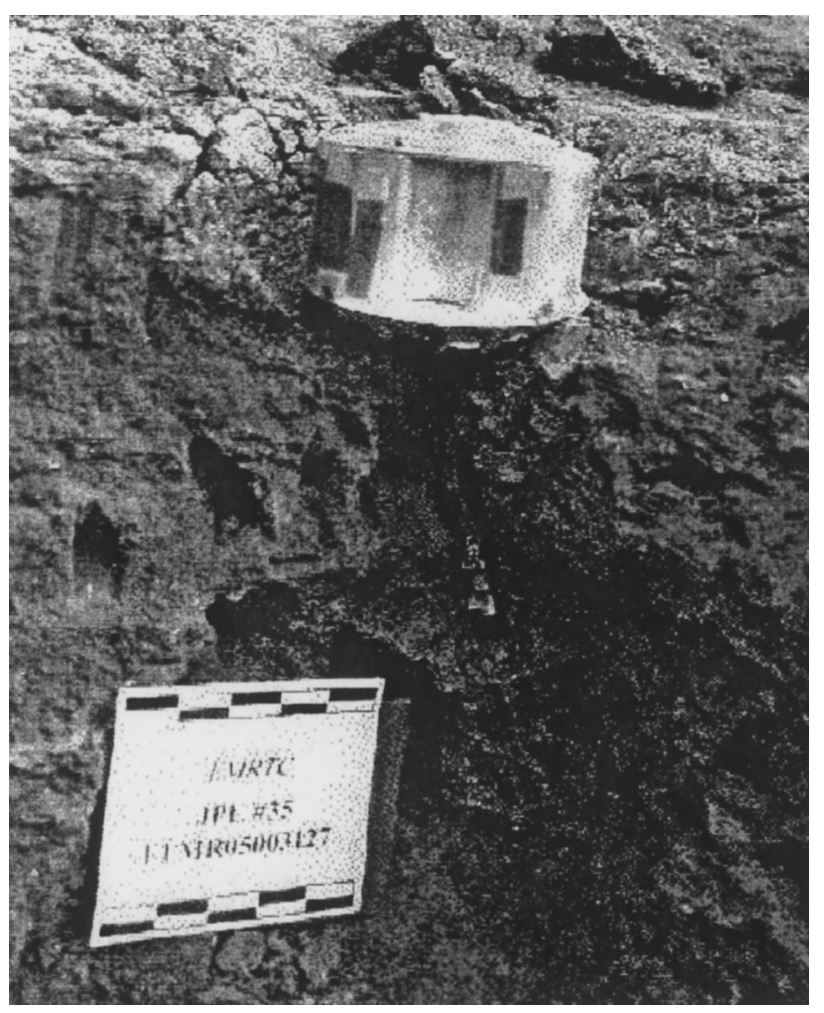

Fig. 5. Prototype DS-2 embedded in ground after a shot (Number 35 in Table 1). The tunnel carved by the forebody is visible below the aftbody, the forebody itself is not visible. 
were unsuccessful - on one occasion the wire broke, and on the other the scope failed to trigger.

Six attempts were made to use an on-board datalogger. On three of these no data was acquired due to a broken umbilical, accelerometer failure or operator error. The 'successful' tests did not yield interpretable data, with the accelerometer signals either over-ranging (possibly due to rigid mounting exciting the devices' resonant frequency), or no signal at all.

Some 'peak' acceleration information was obtained by ball-and-plate accelerometers where a steel ball rested on a flat lead plate and made a circular indentation, the diameter of which corresponded to the inertial force applied to the ball. This measurement was made only on some of the earliest tests.

\subsection{Penetration depth results}

The depth of penetration of both fore- and aftbodies was measured after each test (Fig. 5), together with the rest angles.

The penetration depth, which can be obtained on Mars by double-integration of the accelerometer signal, provides a quick (albeit crude and indirect) measure of the surface 'hardness', in that the penetration depth can be compared with the terrestrial impact cases. This 'hardness' relates to the strength, density, cohesion and other factors, but for a given target material and penetrator geometry and speed may be considered a constant.

For a given impact speed, the penetration depth relates to the average deceleration, i.e. it can be shown that for an impact velocity $V$ and a penetration depth $D$, the average deceleration is simply $V^{2} / 2 D$, assuming

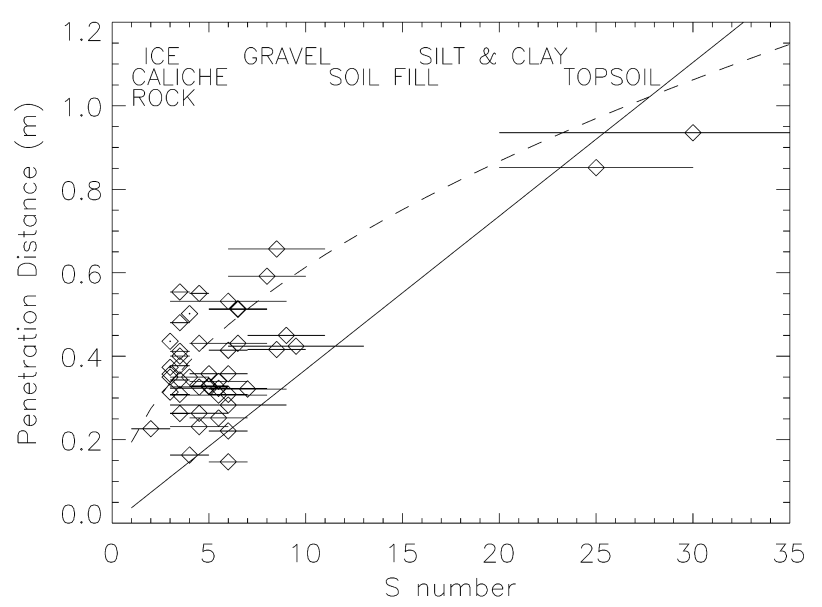

Fig. 6. Graph showing the predicted penetration depth (for $200 \mathrm{~m} / \mathrm{s}$ and $m / A=520 \mathrm{~kg} / \mathrm{m}^{2}$ ) for the Young penetration equation (solid line) and the empirical relation in the text (dashed line). The normalized test data are shown as diamonds with error bars. one-dimensional motion and a rectangular acceleration pulse.

It was noted that in general the rest angle of the forebody was lower than its angle of incidence, i.e. the aftbody evidently begins to rotate to lie flat on the target surface during the early stages of impact, aligning the forebody with the local surface normal.

Penetration depth has been a subject of experimental and theoretical investigation for centuries. One convenient set of relations is due to Young $(1967,1997)$ and parameterizes the target material by a single 'hardness' or 'penetrability' number $S$. Fig. 6 shows the measured penetration depth for the tests as a function of this parameter which can be estimated with a hammer/cone penetrometer (see later), These data are compared with predictions from the relation by Young and an empirical equation due to Lorenz et al. (1999) namely:

$D=4.5 \times 10^{-8} S^{0.5}(m / A)^{0.7} V^{2}$

where $D$ is the forebody penetration depth in metres, $S$ the penetrability, $m$ and $A$ the mass (kg) and cross-sectional area $\left(\mathrm{m}^{2}\right)$ of the forebody and $V$ the impact velocity $(\mathrm{m} / \mathrm{s})$. Like the equation due to Young it is dimensionally inconsistent, and yields no particular insight into the penetration process, but it has the advantage of simplicity and convenience.

This expression includes no term for the impact geometry (angle of attack and angle of incidence). Fig. 7 shows that there is no strong systematic dependence of penetration on these parameters, at least over the modest range over which they were varied during these tests.

One reason for the relatively poor performance of Young's relation (developed for rather larger penetrators) is that in these tests for only a small range of

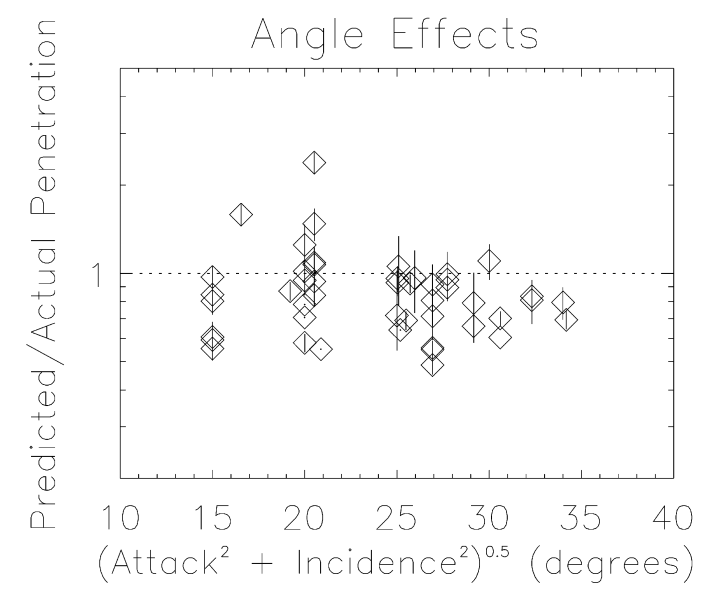

Fig. 7. Test data, shown relative to the prediction from the empirical equation in the text as a function of combined incidence and attack angle. No consistent trend is seen. 
target hardness (3-8) a wide range of penetration depths were encountered. That said, the penetration depth (and by implication, the accelerometry measurement) should be easily able to discriminate between hard $(S<10)$ and soft $(S>20)$ targets.

Different projectile shapes and speeds will give different weights to the various target properties - a higher speed impact applies greater weight to the target density whereas low speed penetration (such as the penetrometer used to measure $S$ ) is more significantly affected by the target bearing strength. Similarly, a sharp, slender penetrator may suffer more from frictional forces along its body, whereas a short, blunt one will be more sensitive to target bearing strength and density. Thus the non-unity exponent on the $S$ term above should not be a great surprise.

Nonetheless, it is clear that more modeling work needs to be done - although both relations above work, neither is dimensionally consistent. Furthermore, to fully exploit the data from Mars, a methodology that relates the instantaneous deceleration to the target properties at that depth is required. Although progress in these directions is being made (e.g. Forrestal and Luk, 1992; Kömle et al., 1997), no totally satisfactory algorithm has yet been published. It is also clear (see Section 5 and Fig. 18) that the combined and separate dynamics of the fore- and aft-bodies need to be considered as delayed separation appears to be a significant factor in penetration performance.

\section{Low-speed Arizona tests}

A second series of tests is underway at the University of Arizona (Lorenz, 1999), using a smaller airgun capable of vertical impacts at up to about $50 \mathrm{~m} / \mathrm{s}$. Although at lower impact speeds than for the DS-2 flight units, the rapid turnaround of tests (several per day) and the ability to closely control the target strati-

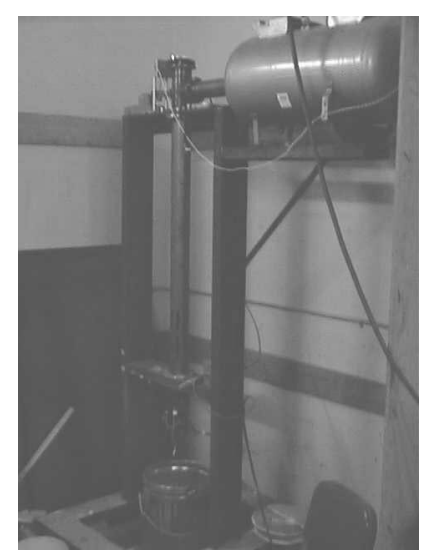

Fig. 8. Airgun at Arizona. The vertical barrel is about $2 \mathrm{~m}$ long.

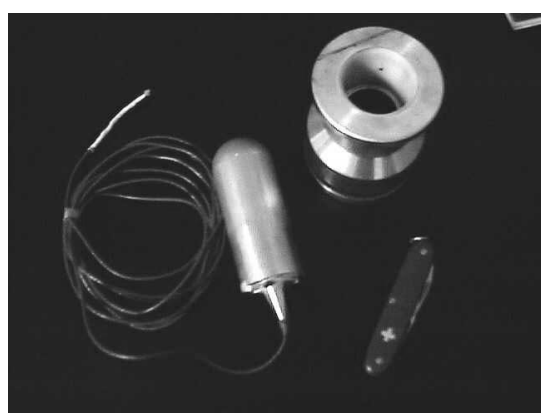

Fig. 9. Projectile components used in test at Arizona. The kevlar-reinforced cable carries the signal from the piezoelectric accelerometer in the back of the cylindrical forebody. The sabot/aftbody is at the upper left; the dark line on the sabot indicates where a pencil lead in the speedometer impacted upon it.

graphy enable these tests to provide valuable information.

The air gun facility (Fig. 8) was developed for the CRAF (Comet Rendezvous and Asteroid Flyby, sadly cancelled in 1992) penetrator, and subsequently used in a development program for projectile sample acquisition by tethered hollow-nose penetrators (Boynton et al., 1996). The gun consists of an $8 \mathrm{~cm}$ diameter vertical barrel, connected via a large-bore solenoid valve to an air tank, all mounted on a steel support frame. After pumping the tank to several bar, opening the valve accelerates a projectile $(\sim 1 \mathrm{~kg})$ as a free piston down the barrel. Impact speed is determined by timing the breaking of two electrically-conducting pencil leads spaced $15 \mathrm{~cm}$ apart (this was found more reliable than the conventional light beam technique). Graphite pencil leads have the advantages of easy procurement and low cost, yet are both stiff and brittle giving a crisp break in the circuit while absorbing very little of the projectile's energy.

\subsection{Experimental setup}

For DS-2 tests, the projectile is an aluminium sabot (Figs. 9 and 10), carrying a penetrator representative of the DS-2 forebody in shape and mass (i.e. a $730 \mathrm{~g}$

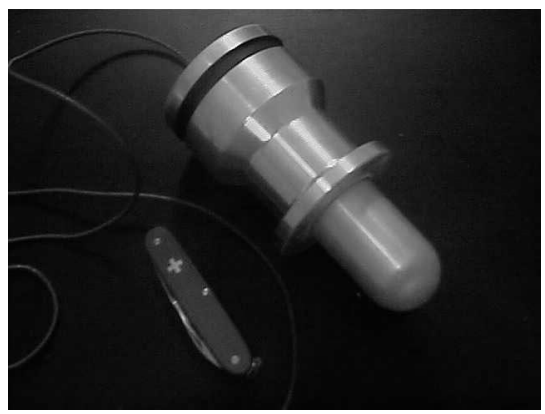

Fig. 10. Assembled Test article. The black recessed band on the sabot indicates where a graphite shear pin holds the projectile inside the gun barrel. The cable is coiled inside the rear part of the sabot. 
sphere-nosed steel cylinder, $4 \mathrm{~cm}$ in diameter and $10 \mathrm{~cm}$ long). The penetrator carries an Endevco 2225 piezoelectric accelerometer, the signal from which passes along a coaxial cable (coiled inside the sabot prior to firing) back up to a feed-through at the breech (top) of the gun barrel. The signal passes through a charge amplifier and is recorded at $10 \mathrm{ks} / \mathrm{s}$ with 16 bits accuracy by a laptop computer with an Iotech Daq-216B data acquisition card. The same acquisition system simultaneously records the voltage across a resistor network that includes the two leads for speed measurement, i.e. when the top lead is broken the voltage on this signal jumps from 3 to $5 \mathrm{~V}$, and then drops to zero when the bottom lead is broken.

In a typical medium-speed shot, the tank is pumped to $44 \mathrm{psi}$ (400 $\mathrm{kPa}$ absolute), which coincidentally produces an impact speed of $44 \mathrm{~m} / \mathrm{s}$, or a $3.2 \mathrm{~m} / \mathrm{s}$ pulse on the speed measurement channel. For this mass of penetrator + sabot, impacts of $60 \mathrm{~m} / \mathrm{s}$ are possible (limited by the 100 psi rating of the air tank), although lighter projectiles may be shot faster.

The target is set up in a steel bin below the airgun. Tests to date have used sand and layers of sheetrock (i.e. plaster) and gravel, although in principle any target can be set up. A $45 \mathrm{~cm}$ bin is now being used some edge effects are implied in a $35 \mathrm{~cm}$ diameter steel bin used initially - the force pulses of impact split the seams of the bin after about six shots.

Additional tests which are presently underway with this facility will explore the thermal effects of impact and will be the subject of a future paper.

\subsection{Test results}

It was found that in most tests, but especially those using soft targets, the penetrator forebody only barely separated from the sabot. A reliable, if crude, way of ensuring separation was to place an aluminium and plywood sheet over the target, with a hole slightly larger than the forebody, but smaller than the sabot, such that the sabot is halted ('stripped') at the surface.

Initially kevlar-reinforced coaxial cables were used. After a few shots, these tended to acquire small nicks in the outer layer of insulation. Although the kevlar fibers within this outer layer were not damaged, most of the cable's modest rigidity is due to the outer PVC layer, such that a nick tended to concentrate bending. The kevlar reinforcement, while reducing the likelihood that data would be lost during a shot due to the cable being pulled, did not significantly extend the lifetime of the cable. Since non-reinforced cables were a factor of two less expensive, these were used in subsequent tests.

A typical dataset is shown in Fig. 11. The dashed profile shows the speed measurement channel, with a characteristic square-wave pulse; the upper, solid, line is the accelerometer signal (a negative voltage implies a vertically upwards acceleration). Note the spike at the start of the trace - this is an unintended (but useful) electromagnetic coupling of the solenoid current into the accelerometer circuit, indicating the valve actuation. The pressure behind the penetrator rapidly builds up, until a shear pin holding the projectile at the top of the barrel breaks, producing a step (with some ringing superimposed) in acceleration. This drops with time until the spike and abrupt drop in acceleration signal at $t=635 \mathrm{~ms}$ indicates the muzzle of the barrel. Then the projectile passes through the speedometer note the slight acceleration spike when the second lead is broken.

The drop in accelerometer signal is due to several factors, although the relative importance of each has not yet been determined. Firstly, as the fixed mass of gas from the tank expands into the increasing volume of the barrel behind the projectile, the pressure behind the projectile falls. This reduction in pressure may be

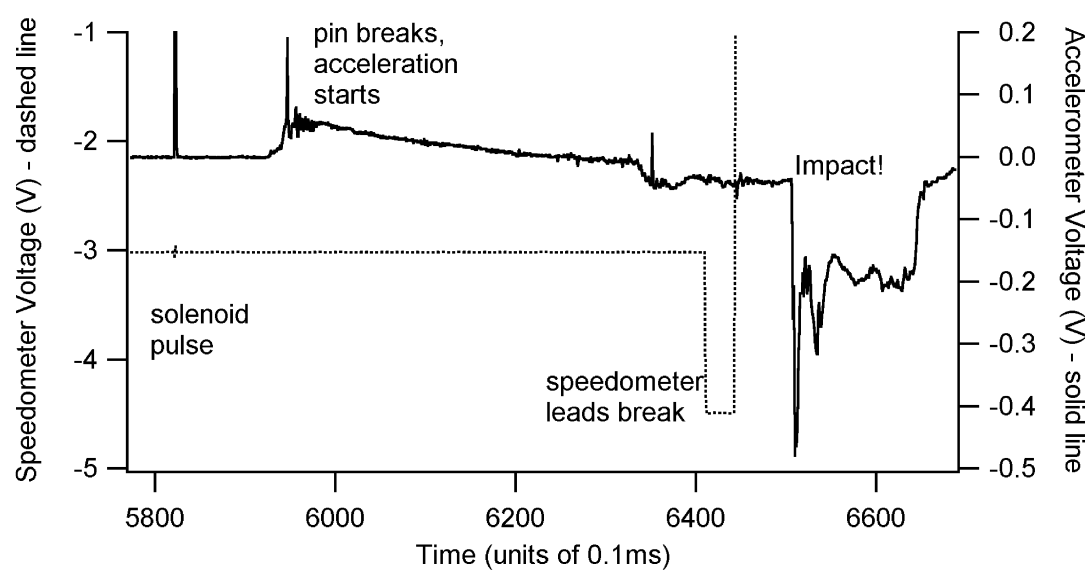

Fig. 11. Full raw dataset from UA gun shot. Solid line is the accelerometer voltage (right hand scale) dashed line is speedometer signal (left-hand scale). 
exacerbated by possible restrictions in flow from the tank past the valve. Another aspect is that a small but non-zero leakage current in the charge amplifier will cause a constant acceleration (constant charge) to decay away.

Shortly after speedometer passage, impact occurs. The target here was sand, with a single $1.2 \mathrm{~cm}$ layer of sheetrock above - the sheetrock produces the large initial pulse, and the signal thereafter is moderately flat at $\sim 500 \mathrm{~g}$ (see also Fig. 21 later) until the penetrator comes to rest. The second, triangular spike in the impact signature may be related to the separation of the forebody from the sabot - further tests are underway to elucidate this phenomenon, which may be an issue for the 'real' DS-2 probes, which are retained in the aftbody until impact in a similar way (shear pins). The first sheetrock pulse may also be faintly representative of the aeroshell fracture of the flight probes on impact (which will occur before the fore- and aftbodies separate).

Firstly it has been indicated in these lower speed tests that layers with spacing of $5-10 \mathrm{~cm}$ can be resolved (Fig. 12a,b). The limitation is probably the nose diameter, which averages soil forces over several $\mathrm{cm}$, rather than the number of samples per centimeter, which is a factor $\sim 2$ poorer on flight than for these tests. It has also been found that fine structure in the accelerometer record may indicate 'microstructure' (at the centimeter level); tests indicate (Fig. 13) that a high frequency 'noise' component is found in coarse gravel targets that is not present in finer-grained materials.

A piezoelectric accelerometer was chosen for its modest cost and ease of use (in particular that it provides enough signal to drive the long cable and needs no excitation voltage.) However, some difficulties are

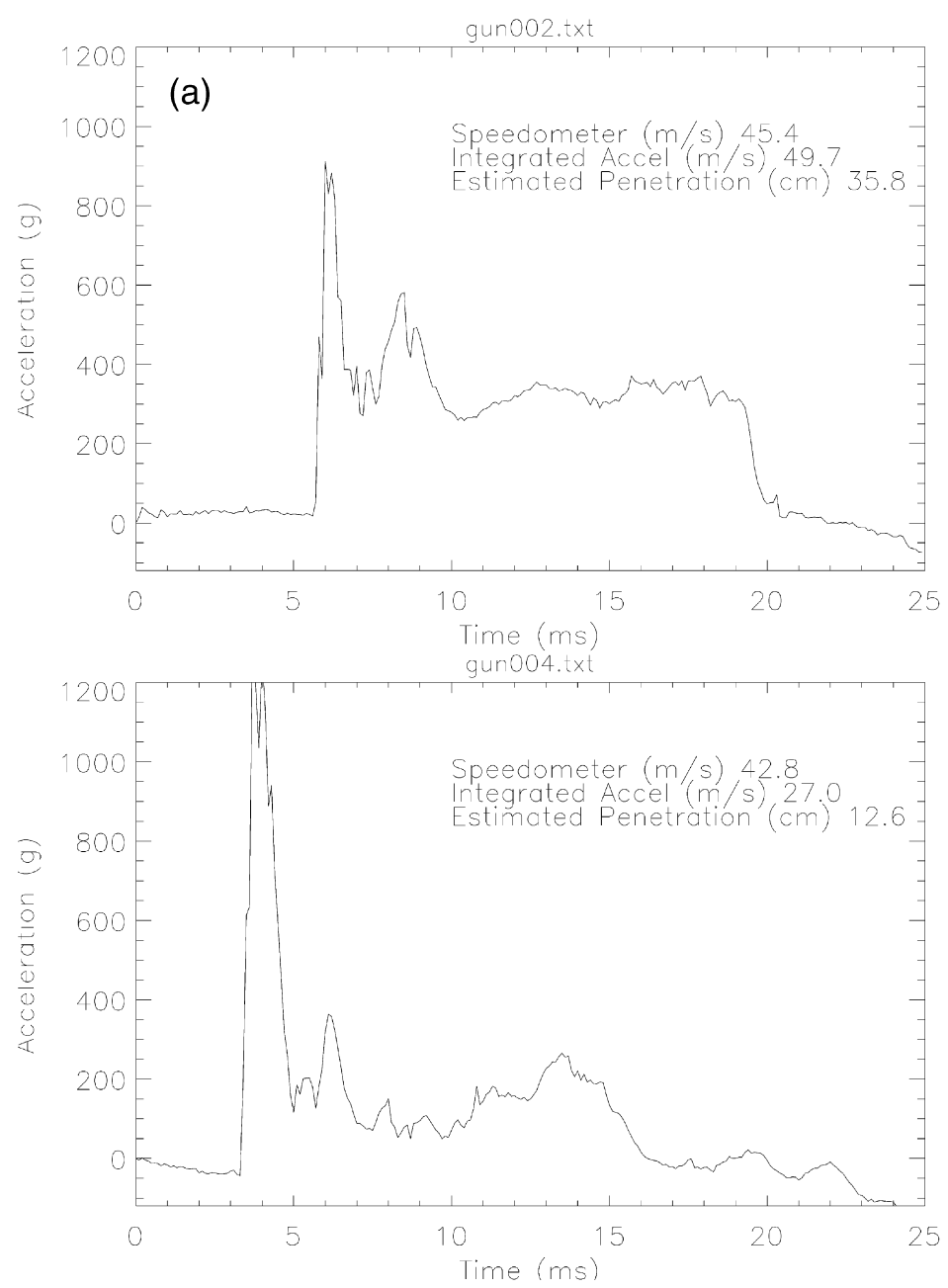

Fig. 12. (a) Two shots into sand/sheetrock targets at Arizona. As can be seen, zero offset drift is a problem; signal integration inaccurately estimates impact speed and penetration depth, which was about $20 \mathrm{~cm}$ for both shots. Top target was one layer of sheetrock on sand; bottom had two layers, spaced only $3 \mathrm{~cm}$ apart - the separate peaks have almost completely merged. The triangular peak may be related to separation from the sabot. (b) More shots into sand with two sheetrock layers (upper figure; layers spaced by $7 \mathrm{~cm} ; 12 \mathrm{~cm}$ for bottom figure. Actual penetration depths were both $12-14 \mathrm{~cm}$. The flat data at $7 \mathrm{~ms}$ in the lower figure seems anomalous and may be an electrical artifact. 


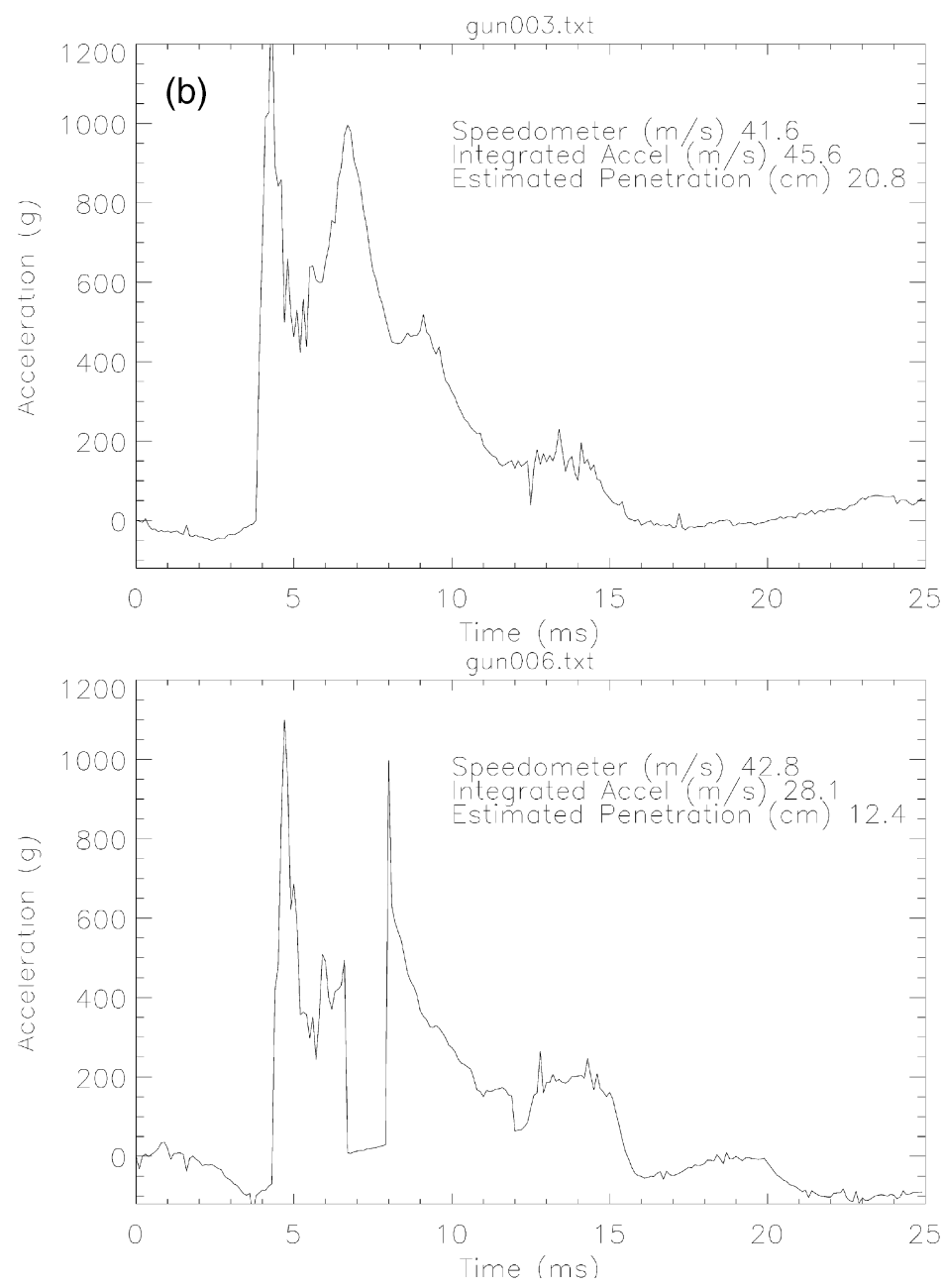

Fig. 12 (continued)

apparent. Firstly, the quantitative integration of the signal appears problematic and fails to reproduce the impact velocity; secondly, double integration similarly is unreliable in determining the penetration depth. It may be noted that Kömle et al. (1997) also report difficulties with piezoelectric accelerometers in similar experiments.

Nevertheless, these tests have shown the qualitative ability to discriminate layers of material, and have shown the characteristic signature of large-grained materials. Further experiments are planned, after a refinement of the sabot design to permit easier separation.

\section{EMRTC accelerometry tests}

The third set of tests was performed in April 1999. These used the same Sandia airgun at EMRTC at the $1 \mathrm{~K}$-West range in Socorro. The probe forebody had the same shape and tungsten nose as that used on flight, so had broadly similar mass properties, although flight components such as the sampling drill and the prism of circuit boards carrying the microcontroller were absent (thus the mass was $605 \mathrm{~g}$, rather than $670 \mathrm{~g}$ on flight). The $z$-axis accelerometer was installed in the same location as for flight.

Two additional accelerometers were installed to record $x$ - and $y$-axis accelerations during impact. All the accelerometers were Endevco 2270-60 K units, a micromachined piezoresistive design. These are internally the same as the 5270-60 K devices on the flight units, although with somewhat different packaging. The nominal sensitivity is $2.57 \mathrm{mV} / \mathrm{g}$ with a $10 \mathrm{~V}$ excitation voltage, and the devices are sensitive over the $0-50 \mathrm{kHz}$ frequency range. Additionally, the voltage across a bridge of resistors was measured, to detect any transients in the excitation voltage applied to the accelerometers that might be erroneously attributed to a 'real' acceleration spike.

The excitation voltages to the accelerometers, and 
the signals from them, were carried along a flight-like umbilical - a kapton tape with conducting tracks about $1 \mathrm{~m}$ long, which unfurls concertina-like when the forebody separates. The aftbody was machined from T7075 aluminium alloy and had the same diameter as the flight units. It is rather longer and therefore heavier $(2315 \mathrm{~g})$ than flight $(1816 \mathrm{~g})$, in order to accommodate redundant batteries, $g$-switches and a datalogger.

The batteries used to drive the data logger are conventional $9 \mathrm{~V}$ alkaline cells, rewired and repackaged in epoxy: the higher capacity Lithium-Thionyl Chloride cells used on flight are more expensive and can explode on impact if used incorrectly, presenting an undesirable safety hazard. The datalogger is a rugged unit manufactured by IES, rated at $100,000 \mathrm{~g}$ with a stainless steel case and incorporates a 12-bit $250 \mathrm{ks} / \mathrm{s}$ analog-to-digital converter.

The datalogger and batteries were held in the aftbody by paraffin wax, which also prevented cabling from being flexed during impact. Cables were held in place, and the wax was prevented from fouling the umbilical during wax pouring, by 'silly putty', a coloured elastomer. The wax was removed with the aid of a hot-air gun to allow repacking of the umbilical and replacement of the batteries after each shot.

The nominal operation was intended to be as follows: after checkout and prior to bolting of the lid, the datalogger would be armed, placing it in a low-power but ready state. The projectile would be glued into its foam sabot, and loaded into the gun, static friction being enough to hold the projectile in the barrel. When the gun was fired, the acceleration in the barrel would activate the first $g$-switch $(+50 \mathrm{~g}$ threshold) and place the datalogger into a high-current sampling mode. Upon impact, the second $g$-switch would trigger, freezing the following $25 \mathrm{~ms}$ of data in the memory buffer. After the gun had been safed, the projectile would be dug out of the target and taken to the bun-

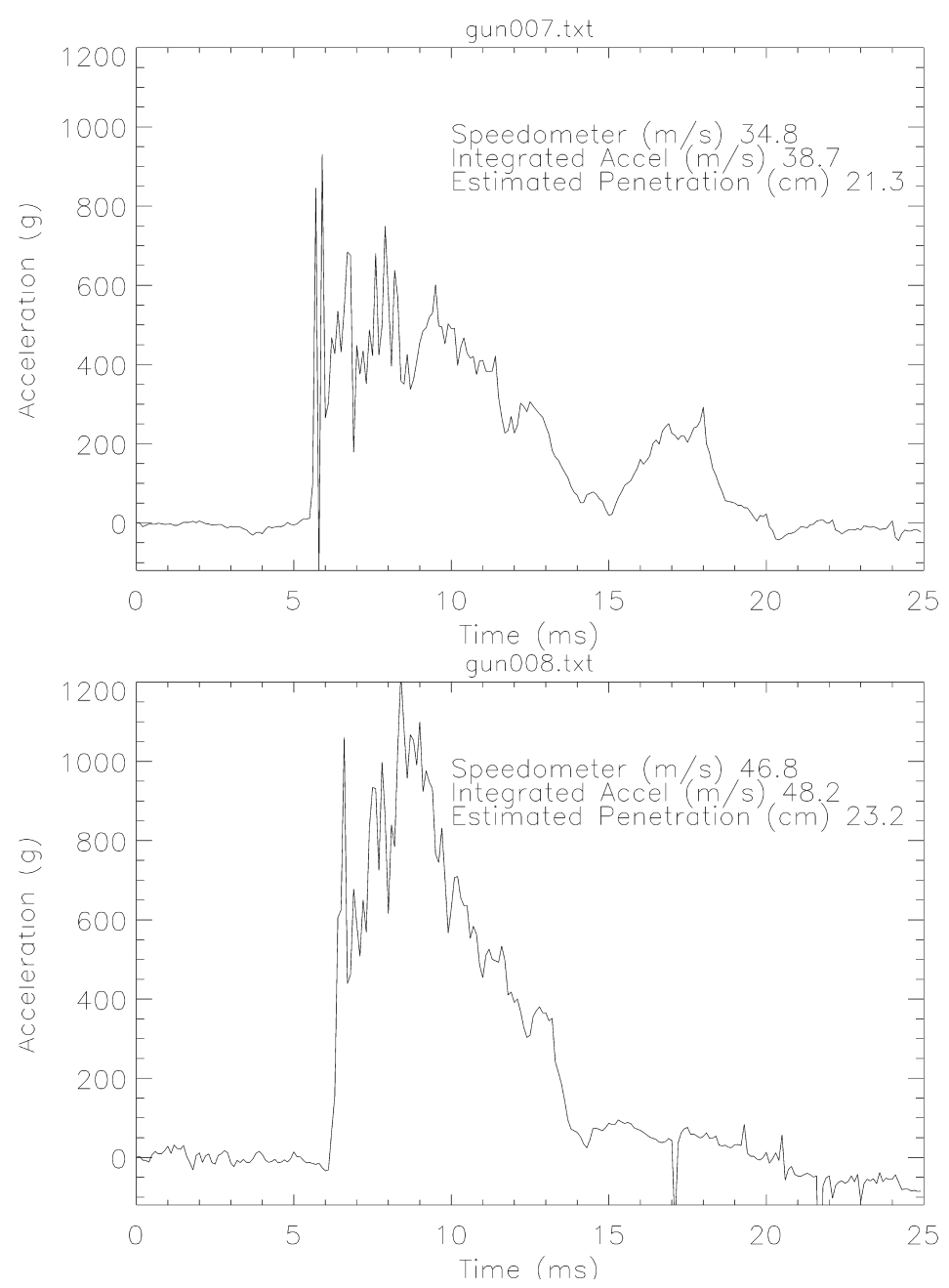

Fig. 13. Two shots into gravel (1-2 cm granite lumps). Actual penetration was about $5 \mathrm{~cm}$ and $10 \mathrm{~cm}$, respectively. Note the strong high frequency component. 
ker where its data would be downloaded into a laptop PC.

During checkout at EMRTC, the functionality of the first (50-g) $g$-switch could not be demonstrated. Drops onto the floor and hammer blows failed to trigger it, even though the second $300 \mathrm{~g}$-switch could be triggered in this way. It is possible that these crude tests did not generate a wide enough acceleration pulse to trigger the switch, but it was decided not to leave the tests at risk of failure due to this switch. Instead, both arming and high-current triggering were performed manually. Since battery lifetime in this high current mode was limited, this meant that attachment of the probe rear cover, mounting in the sabot, loading and firing would have to be performed within a couple of hours. This in fact proved not to be a problem, and indeed provided a useful incentive to keep to the test schedule, which with seven shots in four days, was quite aggressive. To save time, the laptop and interface were brought out to the impact site after the shot, and the probe datalogger was downloaded in situ (Fig. 14).

All tests were performed at $0^{\circ}$ angle of attack, and $10^{\circ}$ incidence.

\subsection{Target preparation and characterization}

The targets were assembled in a culvert about $1 \mathrm{~m}$ deep. The two materials used were the local clay and Oklahoma sand, a fine white silica sand. Rain about 4 days prior to the tests made the sand somewhat damp (damp enough that hand pressure would just form a consolidated lump).

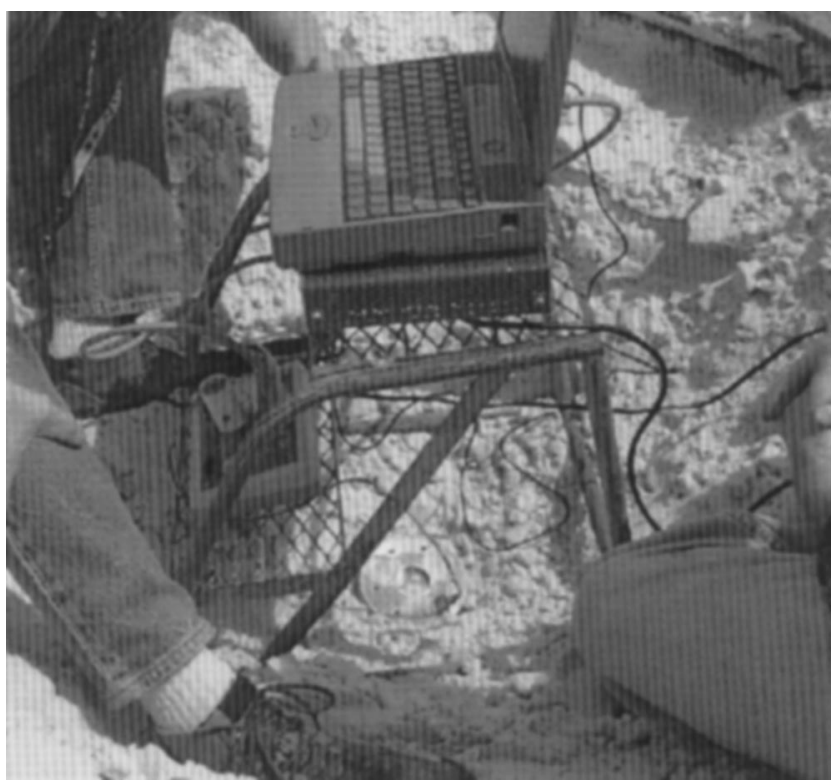

Fig. 14. Downloading the data from the penetrator (disc at lower center). Little or no sand has been removed during the installation of the computer - the impact and/or the airblast excavated the crater seen here (Photo: J. Moersch).
The local New Mexico clay was used for other tests. In general, targets were assembled by shoveling the material into the culvert about 6 in depth at a time, then packing with a pneumatic hammer. The strength of the target at each step was verified using a standard penetrometer, and additional packing performed if required.

This penetrometer (Young, 1968) is a steel rod with a $1 / 2$ in $(12.7 \mathrm{~mm})$ diameter 30 degree half-angle cone at its tip. A brass weight, of $\sim 5 \mathrm{~kg}$ mass, is raised by hand to an end stop and is allowed to fall under gravity until it hits a lower end stop (Fig. 15). This usually propels the whole assembly into the target a short distance. The number of drops, or blows, to achieve $30 \mathrm{~cm}$ of penetration is a measure of the target hardness. Specifically, this number is related to the penetrability index or ' $S$-number' by the curve in Fig. 16, described approximately by the relation:

$S \sim 60 /\left(N^{0.55}-2\right)$.

Targets were also evaluated with a static penetrometer (BK model AP-2100-1). This device has a cone similar to that on the standard penetrometer, but instead of a

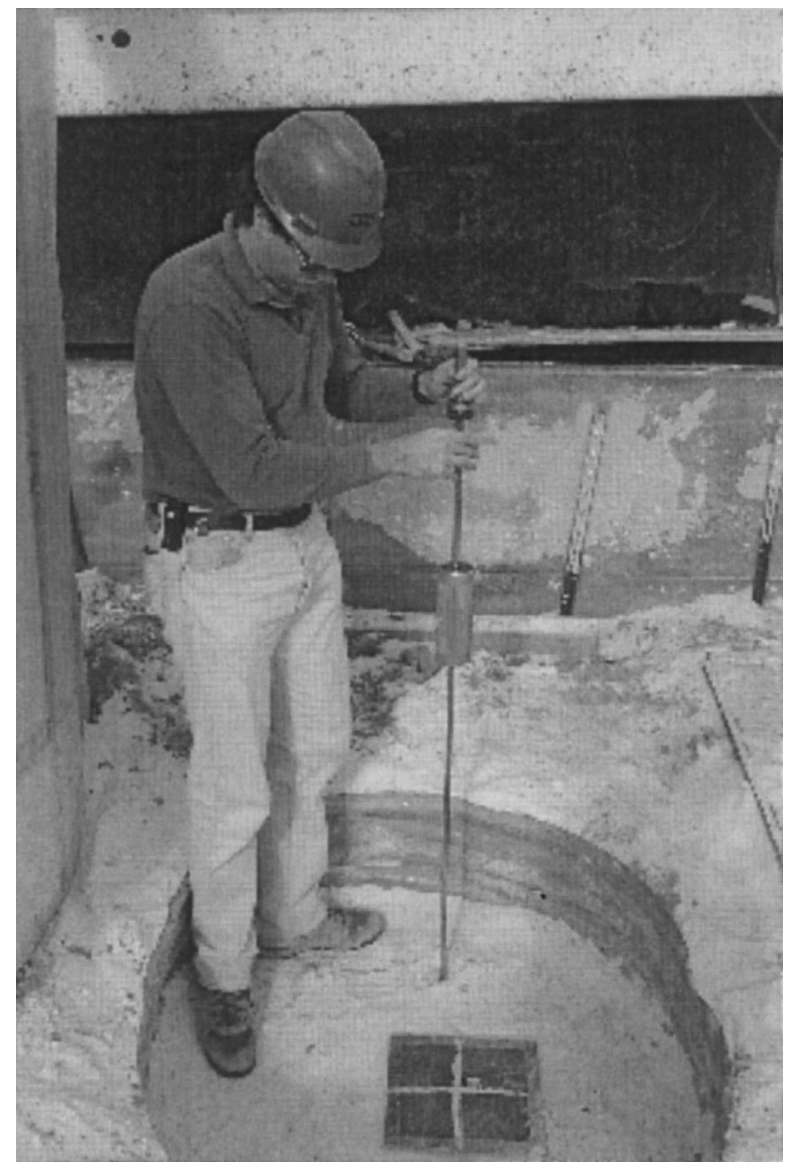

Fig. 15. Testing the hardness of the target at EMRTC. To the left is the X-ray film panel. Square with cross is a panel simulating the entry shell of the penetrator (Photo: J. Moersch). 


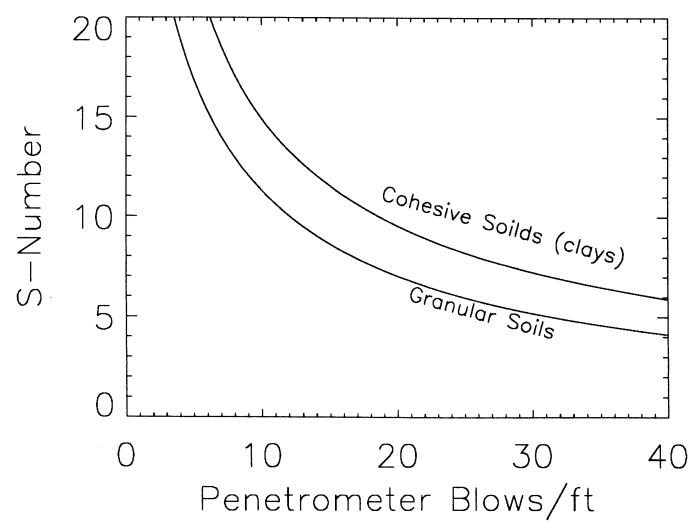

Fig. 16. Relationship of ' $S$-number' to the parameter recorded onsite, namely the number of blows of the penetrometer per foot $(30 \mathrm{~cm})$ of penetration.

hammer weight has a handlebar on which the operator's body weight can be applied; a force gauge allows the instantaneous and peak bearing strength to be read. Various types of penetrometer are discussed and compared in Sanglerat (1972).

The results of this instrument are compared with those of the standard penetrometer for the sand and clay targets, and for a finely crushed limestone ('moondust') also present at the test site, in Fig. 17. In general the two measures correlate well.

For the first four tests, a temperature probe was installed in the target material and the results from this sensor are described in a separate paper (Lorenz, 1999, in preparation).

\subsection{Results}

The test conditions for these tests are summarized in Table 2.

The first test into sand revealed several surprises, but good data was obtained. It was noted from a remote video camera that a large amount of target ma-

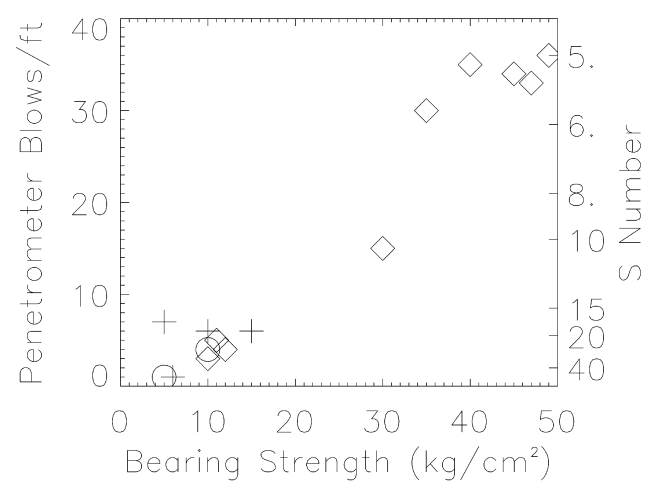

Fig. 17. Correlation of penetrometer blows required to penetrate $30 \mathrm{~cm}$ with the cone bearing strength. Symbols indicate different soil types (diamonds - clay; crosses - sand and circles - a powdered limestone). terial was ejected; it is conjectured that the air blast from the gun (whose muzzle was only $\sim 3 \mathrm{~m}$ away) may have contributed significantly to the target excavation - an approximately conical crater $30 \mathrm{~cm}$ deep was formed.

Unfortunately, the probe forebody did not separate from the aftbody. At the time it was felt that contributing factors may have been the breakwires used to trigger the X-ray camera, the softness of the target (unreliable forebody separation had been noted in the UA tests into soft targets) and damage to the shear pins during the characterization of the $g$-switch. The lower differential area/mass ratio (i.e. the ratio of the forebody area per unit mass to that of the aftbody) of the test article compared to flight, and to most of the development test units was noted (but could not be fixed on site).

A number of tests in the development phase were subsequently considered in this light - a plot of separation distance against mass loading shows (Fig. 18) that the separation for broadly similar target hardness and impact speed does correlate with mass loading ratio. For the flight condition, with a ratio of 4.0, separation should occur, but with the 2.6 value in these tests, separation is marginal.

Surprisingly, there were significant amounts of sabot material ahead of the aftbody (the yellow foam material was obvious against the brilliant white of the sand or the reddish clay. It is not clear how the sabot, initially behind the probe, could end up ahead of it (see Fig. 3).

Test 2 fired at a lower-than-planned velocity due

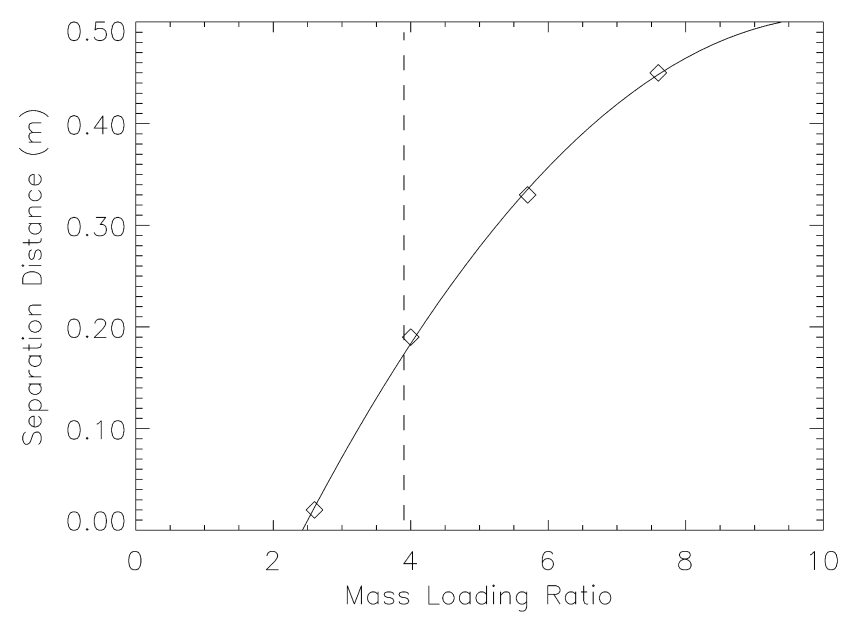

Fig. 18. Separation distance between fore- and aft-body in soft targets $(S \sim 20)$ as a function of the relative area/mass ratio of fore and aft-bodies. Although the instrumented EMRTC tests $($ ratio $=2.6)$ failed to separate cleanly, the flight units (dashed line) should do so. The relationship is not linear - ultimately (with a light forebody, stuck arbitrarily shallow on the surface, the separation distance becomes simply the penetration distance of the constant-sized forebody). 
Table 2

Parameters of third set of tests ${ }^{\mathrm{a}}$

\begin{tabular}{|c|c|c|c|c|c|c|c|c|}
\hline \multirow[t]{2}{*}{ Shot } & \multirow[t]{2}{*}{ Target } & \multirow[t]{2}{*}{$\mathrm{S}$} & \multirow[t]{2}{*}{ Velocity $(\mathrm{m} / \mathrm{s})$} & \multicolumn{2}{|c|}{ Penetration $(\mathrm{cm})$} & \multicolumn{2}{|c|}{ Rest angles } & \multirow[t]{2}{*}{ Notes } \\
\hline & & & & FB & $\mathrm{AB}$ & FB & $\mathrm{AB}$ & \\
\hline 1 & $60 \mathrm{~cm}$ sand on soft clay & 18 & 180 & 35 & 31 & $+10^{\circ}$ & $+10^{\circ}$ & Forebody did not separate \\
\hline 2 & $60 \mathrm{~cm}$ sand on soft clay & $18-20$ & 167 & & & & & Penetrator skipped and did not separate \\
\hline 3 & Hard packed clay & $4-6$ & 203 & 42 & 21 & $-4.8^{\circ}$ & $-6.5^{\circ}$ & Good separation \\
\hline 4 & Medium packed clay & $9-11.5$ & 194 & 48 & 31 & & $-4.1^{\circ}$ & Good separation \\
\hline 5 & $60 \mathrm{~cm}$ sand on hard clay & $20 / 6-7$ & 199 & 37 & 35 & & $+19^{\circ}$ & Forebody did not separate \\
\hline 6 & $30 \mathrm{~cm}$ sand on hard clay & $20 / 6-7$ & 194 & & & & & Skip \\
\hline 7 & Hard clay & $5-7$ & 193 & 51 & 11.75 & $-10.5^{\circ}$ & $-7.1^{\circ}$ & Umbilical test - no data logger \\
\hline
\end{tabular}

${ }^{\mathrm{a}}$ All shots $10^{\circ} \mathrm{AOI} ; 0^{\circ} \mathrm{AOA}$; forebody mass $=605 \mathrm{~g}$; aftbody mass $=2315 \mathrm{~g}$.

to the burst disk in the airgun rupturing prematurely. This test, and test 6 suffered skip. This appears to be a particular problem with soft targets at low velocities; our interpretation is that at lower velocities, the aftbody has time during the impact event to roll forwards and out of the target before it has penetrated sufficiently deeply that rollout cannot occur.

In order to allow for a failure during the tests, and to enable the aggressive test schedule, two identical
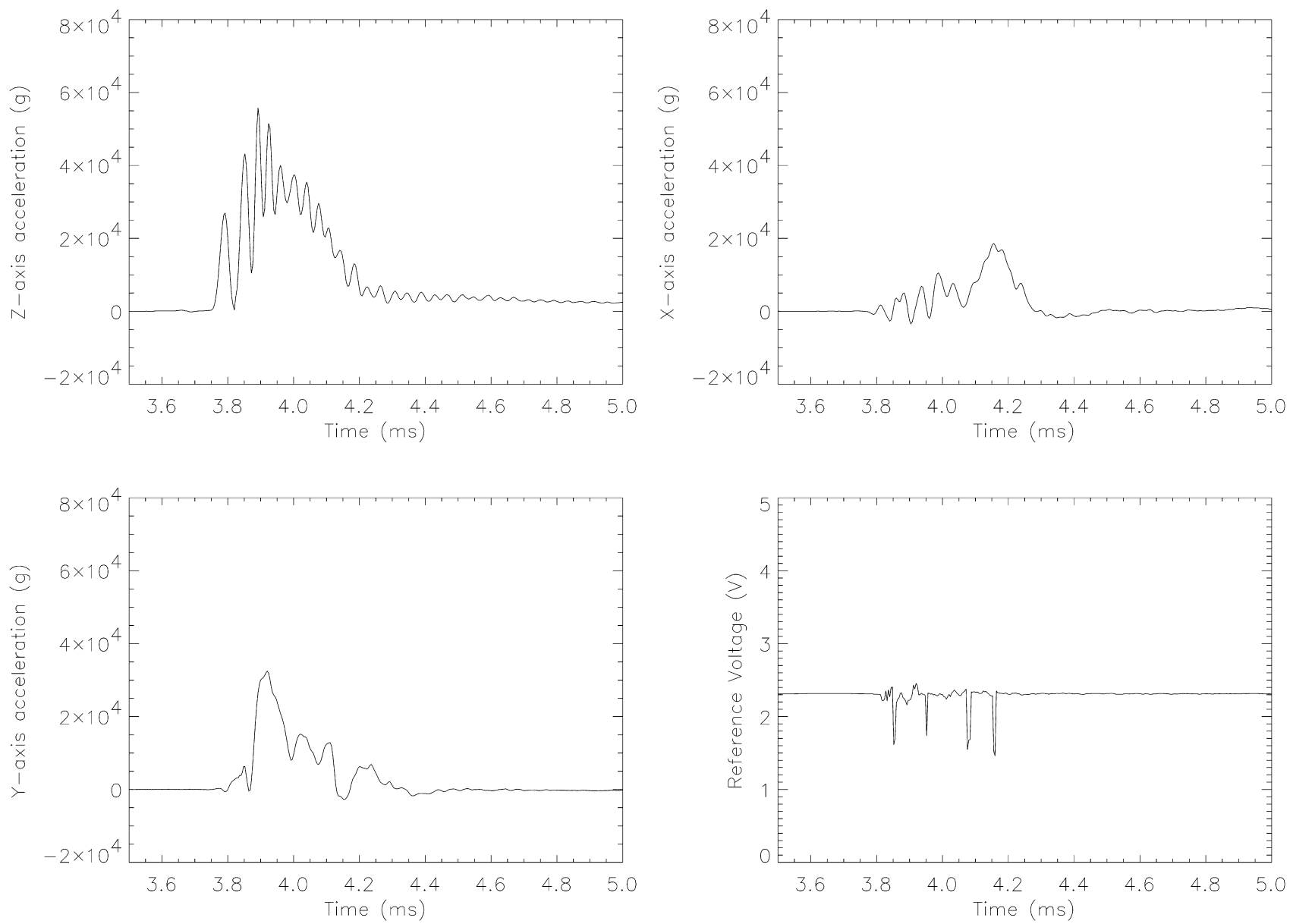

Fig. 19. Accelerometer data from shot (Number 1 in Table 2) into Oklahoma sand. A strong, clean, structural ringing signal is clearly seen superimposed on the $z$-axis data. The $y$-axis signal has a strong initial jump, due to the non-zero angle of incidence, and rotation on impact. The nominally-zero $x$-axis accelerations are more-or-less random, but still quite significant — nearly one-half of the peak $z$-axis signal. In this shot, the forebody failed to separate, so the impact event is over very quickly. Some voltage spikes are evident on the reference channel, but are very short in duration and do not seem to have propagated into the accelerometer readings. Note that the $z$-axis deceleration has not fallen quite to zero in fact it does not do so until about 5 ms later - see Fig. 21. 

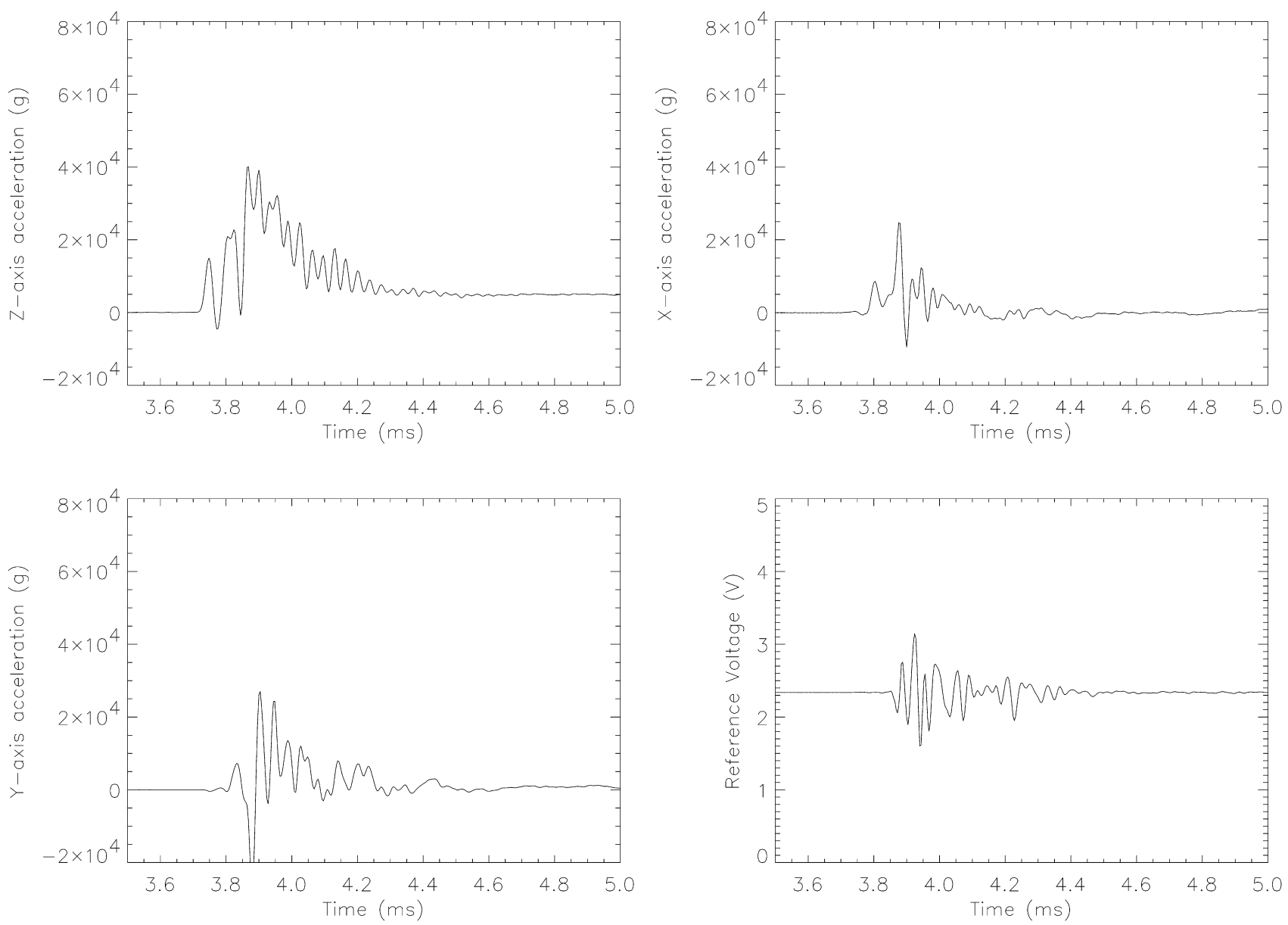

Fig. 20. Results from a shot (Number 4) into New Mexico clay. Curiously, the peak $z$-axis signal is lower than before. Separation does occur, and it is seen that the $z$-axis deceleration (on the forebody alone) stays fairly constant at $4000 \mathrm{~g}$ past $4.5 \mathrm{~ms}$. The clay does not permit the aftbody to rotate significantly - the only $y$-axis signals are short in duration, and apparently correlated with noise on the reference voltage channel, as are the $x$-axis signals, suggesting that these are largely artifacts.

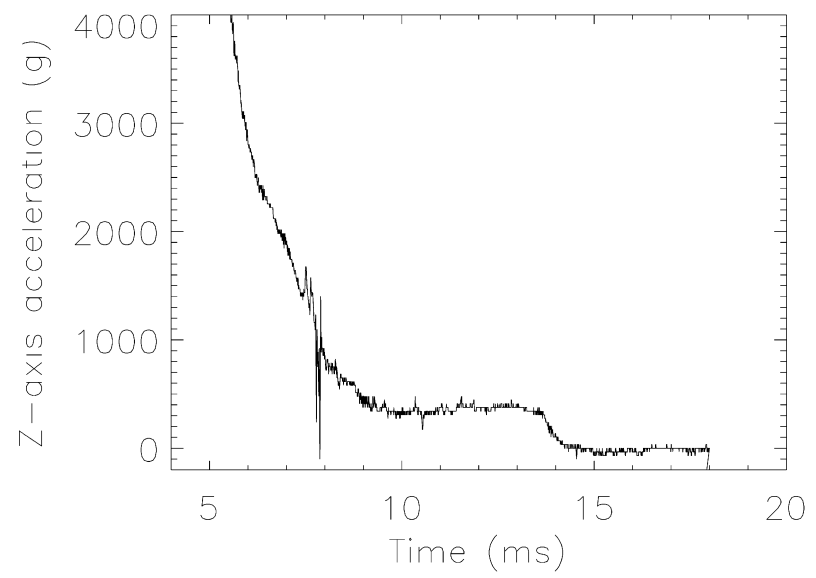

Fig. 21. Continuation plot of $z$-axis data from shot 4 - note the vastly different scales in this Figure and Fig. 20. Deceleration falls rapidly, then there is a transient at $7.8 \mathrm{~ms}$ which is probably related to the separation of fore- and aft-body; the deceleration stays at a constant level of $\sim 500 \mathrm{~g}$ for another $6 \mathrm{~ms}$ before the forebody comes to rest.

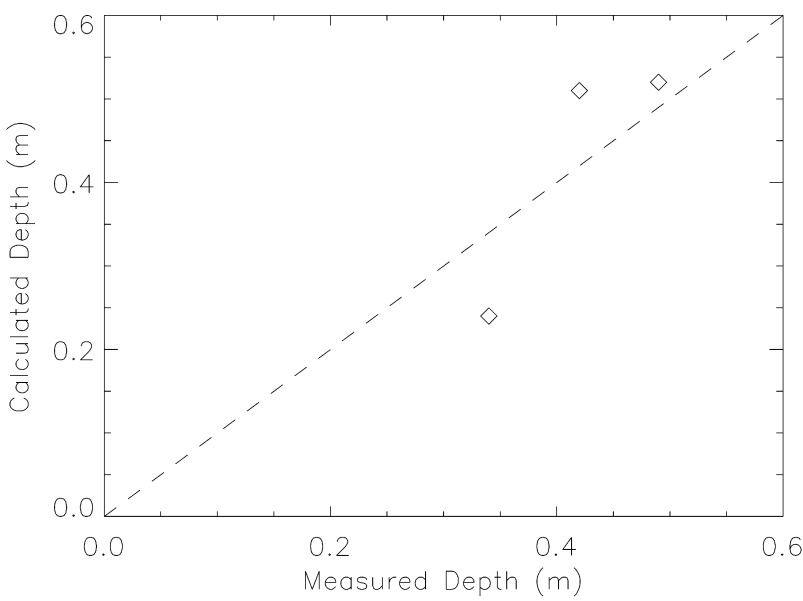

Fig. 22. Calculated depth (from double-integrating the $z$-axis signal, using the known impact velocity, compared with the actual recovered depth of the forebody. Although not perfect, the agreement is generally good. 
test articles were used. The datalogger of one article failed on its third shot (shot 5). This datalogger already showed some signs of damage (its steel case was slightly deformed) so it may have been ready to fail at any moment. Another contributing factor is that the wax holding the components inside the aftbody was possibly rather softer than for the other shots, as the shot took place a mere hour or so after the wax was poured.

The accelerometer data from the shots on which datalogger failure did not occur was of very good quality, being essentially free of noise (Figs. 19 and 20), although shot 6 (not shown) did have a transient spike in its $z$-axis data. Structural ringing is very apparent in the data on all three accelerometer channels, although note that such ringing will not be resolved on flight due to the lower sampling rate. The usefulness of the reference voltage channel is apparent.

Interpretation of the data is not as easy as had been anticipated, since separation was not as reliable as first hoped, and thus the dynamics are predominantly those of the combined fore- and aft-bodies, rather than the forebody alone. In particular, the forebody did not travel far enough to detect the soft:hard target transition depth in shots 5 and 6 , which was a principal test objective.

However, close examination of the latter stages of the shots into clay (shots 3 and 4) which did have good separation (Table 2) indicates a transient spike (shot 4: Fig. 21) which is probably the separation event. A similar feature can be found in the shot 3 data. It may be noted that after this event, the deceleration is more or less constant at about $500 \mathrm{~g}$ until the forebody comes to a halt. This is in encouraging agreement with the deceleration observed in the UA tests (see Fig. 12a).

Double integration of the $z$-axis signal (or, indeed a $25 \mathrm{kHz}$ low-pass filtered and subsampled version of it, representative of flight data) yields a reasonable $(\sim 10 \mathrm{~cm}$ accurate) estimate of the penetration depth (Fig. 22).

\section{Conclusions}

Penetrators are a versatile and exciting vehicle for exploring the subsurface of planetary bodies, but their violent emplacement necessitates careful design and laborious tests, especially if the accelerometer record of impact is to be fully interpreted. It is hoped that the experiences described above will be useful in future missions.

Some specific conclusions include the following points.

1. The forebody to aftbody mass loading ratio should be four or higher to ensure a clean separation. Combined fore- and aft-body dynamics are required to fully interpret accelerometer data from this type of vehicle.

2. Piezoelectric accelerometers without built-in amplifiers are qualitatively useful, but quantitatively are difficult to get reliable results from.

3. It is important to obtain as much diagnostic information on the target material (shear strength, density, etc.) for penetration test results to be useful in a broader context than simple demonstration of survival.

4. It is similarly important to instrument a penetrator as well as possible - the penetration process is violent and many interactions may occur. Multiple methods of speed determination, multi-axis accelerometry measurements and reference voltage monitoring all help in this regard.

\section{Acknowledgements}

This work was supported by the NASA New Millenium Program DS-2 project. We thank the staff of EMRTC and especially Kent Harvey for assistance with the tests. Rick Keaton of Lockheed Martin played a major role in the early tests, and in the design of the datalogger test article. RDL thanks Mike Williams, Bill Verts and Steve Bell for assistance with the UA tests. The reviewers are thanked for useful comments.

\section{References}

Beswick, A.G., 1964. Instrumentation for investigating the physical properties of the lunar surface. In: 19th ISA Conference, New York, October. Instrument Society of America Preprint 16.1-4-64.

Boynton, W.V., Reinert, R.P., 1995. The cryo-penetrator: an approach to exploration of icy bodies in the solar system. Acta Astronautica 35 (suppl), 59-68.

Boynton, W.V., Bailey, S.H., Williams, M., Hanara, D., Lewicki, C., Carroll, J., 1996. The use of small penetrators to return samples and to host instrument packages IAA-L-0905. In: Proceedings 2nd IAA International Conference on low-cost planetary mission. John Hopkins University.

Braun, R.D., Mitcheltree, R.A., McNeil, Cheatwood F., 1997. Mars microprobe entry analysis. In: Proceedings of the 1997 IEEE Aerospace Conference, February.

Forrestal, M.J., Luk, V.K., 1992. Penetration into soil targets. International Journal of Impact Engineering 12 (3), 427-444.

Kömle, N.I., Ball, A.J., Kargl, G., Stöcker, J., Thiel, M., Jolly, H.S., Dziruni, M., Zarnecki, J.C., 1997. Using the anchoring device of a comet lander to determine surface mechanical properties. Planetary and Space Science 45 (12), 1515-1538.

Lorenz, R.D., 1999. Penetrator experiments with the University of Arizona Airgun in support of DS-2 and future missions. In: 
International Symposium on the Mars Exploration Programme and Sample Return Missions, Paris, February.

Lorenz, R.D., Bannister, M., Daniell, P.M., Krysinski, Z., Leese, M.R., Miller, R.J., Newton, G., Rabbetts, P., Willett, D.M., 1994. An impact penetrometer for a landing spacecraft. Measurement Science and Technology 5 (9), 1033-1041.

Lorenz, R.D., Moersch, J.E., Smrekar, S.E., Stone, J.A., Keaton, R.M., 1999. Impact penetration of the DS-2 Mars microprobes. Lunar and Planetary Society Conference XXX.

McCarty, J.L., Beswick, A.G., Brooks, G.W., 1964. Application of Penetrometers to the Study of Physical Properties of Lunar and Planetary Surfaces, NASA TN D-2413. Langley Research Center.

Mizutani, H., 1995. Lunar interior exploration by Japanese Lunar Penetrator Mission LUNAR-A. J. Phys. Earth 43 (5), 657-670.

Moersch, J.E., Lorenz, R.D., 1998. Subsurface structure in the Martian polar layered deposits: the DS-2 impact accelerometer experiment. In: 1st International Conference on Mars Polar Science and Exploration (LPI Contribution 953), Texas, October, pp. 27-28.

Sanglerat, G., 1972. The Penetrometer and Soil Exploration. In: Developments in Geotechnical Engineering, vol. 1. Elsevier, Amsterdam.

Simmons, G., 1977. Surface penetrators - a promising new type of planetary lander. Journal of the British Interplanetary Society 30 (7), 243-256.

Smrekar, S.E., Catling, D., Lorenz, R., Magalhaes, J., Meyer, M.,
Moersch, J., Morgan, P., Murphy, J., Murray, B., PresleyHolloway, M., Yen, A., Zent, A., 1999. The DS-2 Mars Microprobe Mission, Journal of Geophysical Research 104 (E11), 27,013-27,030.

Stone, J.A., Rivellini, T.P., 1998. Configuration evolution of the DS2 penetrator, IAA-L98-0303. In: 3rd IAA International Conference on Low-Cost Planetary Missions, Pasadena, CA, April.

Surkov, Yu A., Kremnev, R.S., 1998. Mars-96 Mission: Mars exploration with the use of penetrators. Planetary and Space Science 46 (11/12), 1689-1696.

Thomas, P., Squyres, S., Herkenhoff, K., Howard, A., Murray, B., 1992. In: Kieffer, H., et al. (Eds.), Polar Deposits of Mars in Mars. University of Arizona Press.

Vasavada, A.R., Williams, J.-P., Paige, D.A., Greeley, R., Murray, B., Herkenhoff, K.E., Bridges, N.T., Bass, D.S., McBride, K.S., 1999. Surface properties of Mars' polar deposits and polar landing sites, Journal of Geophysical Research, submitted.

Young, C.W., 1967. The Development of Empirical Equations for Predicting Depth of an Earth-Penetrating Projectile, SC-DR-6760. Sandia National Labs.

Young, C.W., 1968. Dynamic Cone Penetrometer, SC-DB-68-178. Sandia National Labs.

Young, C.W., 1997. Penetration Equations, SAND97-2426. Sandia National Labs. 